Rabaska

Revue d'ethnologie de l'Amérique française

\title{
Arsenault, Georges. La Mi-Carême en Acadie. Tracadie-Sheila, La Grande Marée, 2007, 160 p. ISBN 978-2-349-72254-6
}

\section{Carmen d'Entremont}

Volume 6, 2008

URI : https://id.erudit.org/iderudit/019998ar

DOI : https://doi.org/10.7202/019998ar

Aller au sommaire du numéro

Éditeur(s)

Société québécoise d'ethnologie

ISSN

1703-7433 (imprimé)

1916-7350 (numérique)

Découvrir la revue

Citer ce compte rendu

d'Entremont, C. (2008). Compte rendu de [Arsenault, Georges. La Mi-Carême en

Acadie. Tracadie-Sheila, La Grande Marée, 2007, 160 p. ISBN

978-2-349-72254-6]. Rabaska, 6, 153-155. https://doi.org/10.7202/019998ar d'utilisation que vous pouvez consulter en ligne.

https://apropos.erudit.org/fr/usagers/politique-dutilisation/ 
Home Music est une belle réalisation qui nous présente un exemple d'un modèle pratique pouvant inspirer d'autres projets du genre.

Ronald Labelle

Université de Moncton

Arsenault, Georges. La Mi-Carême en Acadie. Tracadie-Sheila, La Grande Marée, 2007, 160 p. ISBN 978-2-349-72254-6.

Depuis plusieurs années Georges Arsenault étudie les traditions acadiennes de son milieu, l'Île-du-Prince-Édouard. Il s'intéresse surtout à faire revivre les coutumes disparues ou presque oubliées, ou à les dévoiler à ceux qui n'ont pas eu la chance de les vivre. Après la publication de son livre Courir la chandeleur en 1982, il aspirait à produire une série de petits livres sur les diverses coutumes de ce peuple. Finalement, en 2005, il lançait ce projet en publiant un premier recueil, Noël en Acadie, aux éditions La Grande Marée, et ce fut un grand succès. Après avoir capté l'intérêt du public en lui présentant une fête populaire toujours vivante et célébrée un peu partout dans le monde, il choisit pour son deuxième ouvrage un sujet moins connu qui le passionne depuis longtemps : la mi-carême. La Mi-Carême en Acadie montre l'évolution d'une ancienne tradition française qui a survécu dans quelques communautés acadiennes et québécoises. En fait, la mascarade hivernale a connu un essor considérable dans quelques régions telles que Chéticamp et Saint-Joseph-du-Moine, au Cap-Breton, et Natashquan, au Québec, où la fête s'est étendue sur une semaine entière et prend la forme d'un véritable festival. Ce recueil ethnographique, qui propose un regard minutieux sur tous les aspects de la tradition acadienne, partage des souvenirs intimes et encore bien vifs de la fête ; pour plusieurs, la mi-carême représente la nostalgie de la vie d'antan, mais pour d'autres c'est une réalité vivante. $L a$ Mi-Carême en Acadie est un ouvrage de référence dont le but principal est de renouveler les connaissances sur une tradition presque complètement disparue dans la majorité des régions acadiennes en espérant la faire revivre encore. L'auteur, qui a vécu la tradition chez lui à l'Île-du-Prince-Édouard, a déjà essayé de ravigoter la tradition dans son milieu en publiant des articles sur le sujet et même en courant avec quelques amis, mais sans véritable succès. Comme il le souligne dans son avant-propos, cette publication représente une autre tentative de redonner vie à la tradition ancienne : "Incontestablement, ce livre s'avère la suite logique de mes démarches pour conserver la mémoire de cette vénérable tradition, de la faire mieux connaître et même de la faire revivre » (p. 14). 
L'ouvrage compte dix-sept divisions, touchant sommairement à tous les aspects de la tradition : l'origine, les préparatifs, le déroulement, le costume, la nourriture et la boisson, les chants et la musique, les danses et les jeux, et les discours et les dits. En plus de la mascarade, l'auteur nous fait découvrir diverses autres formes du personnage de la Mi-Carême (p. 31-66) : la distributrice de friandises, cette Mi-Carême solitaire qui livrait des bonbons aux petits enfants sages, la Cigogne acadienne, celle qui apportait les bébés naissants et « traumatisait les enfants » (p. 62), et finalement, la Mi-Carême menaçante, un croquemitaine qui servait aux parents à discipliner les enfants désobéissants. Aussi, il est intéressant de noter que les quatre derniers chapitres sont réservés aux villages qui essaient de ressusciter la tradition et surtout à ceux qui reçoivent toujours la visite annuelle des coureurs de mi-carême. Le livre se termine sur un ton optimiste, rappelant la résistance du peuple acadien et son attachement à ses traditions. Autrefois, la mi-carême était une journée de célébrations qui offrait une pause le troisième jeudi du carême, une période de quarante jours vouée au jeûne et à la pénitence. Toutefois, même si plusieurs ont abandonné le carême, l'esprit de la fête ne fait que s'enrichir. Carême ou pas carême, la fête répond toujours au besoin de faire passer l'ennui et de briser la monotonie de la longue saison hivernale, au besoin aussi de sortir du quotidien et de renouer des amitiés. Même si la tradition a beaucoup évolué depuis ses débuts, la fête continue : «Évidemment, la Mi-Carême se plaît en terre acadienne et elle ne l'abandonnera pas tant qu'on voudra bien l'accueillir » (p. 156).

L'auteur a sollicité de nombreuses sources documentaires : des cartes géographiques, des chansons, des passages d'articles de journaux, des témoignages d'un peu partout en Acadie, plusieurs magnifiques photos et quelques illustrations reconstituent bien la tradition et captent surtout l'esprit de la fête. Une liste des cartes au début aide à situer les lieux abordés et un glossaire à la fin facilite la compréhension d'expressions populaires. Pour ce qui est des témoignages cités dans les encadrés, une liste des collections consultées se trouve à la fin du livre. Chaque attestation est accompagnée du nom de l'informateur et du lieu de la cueillette, mais on ne donne ni la source, ni la date de cueillette, ni l'âge des narrateurs, tous renseignements que les spécialistes auraient trouvés essentiels. Il s'en dégage tantôt une impression d'uniformité qui ne laisse pas toujours apparaître les variations dans le temps, tantôt le sentiment d'un collage des anecdotes disponibles. Enfin, une bibliographie ou des références plus complètes auraient été utiles au chercheur intéressé.

Même si plusieurs aspects du rituel ont été abordés, la conclusion aurait pu être mieux développée. L'auteur aurait pu, par exemple, explorer un peu 
plus la raison d'être de la tradition, surtout le sens qu'elle a aujourd'hui depuis l'abolition du carême, et le phénomène du tourisme culturel qui joue de plus en plus un rôle important dans certains milieux. Aussi, l'ouvrage n'est pas exempt de certaines généralisations, comme celle qu'il tire par exemple d'un article de journal (p. 155) ou d'un seul témoignage. Adressé au grand public, La Mi-Carême en Acadie redonne à la communauté acadienne ce que l'auteur en a reçu et met à la disposition des chercheurs un recueil de témoignages précieux qui renseigne sur la richesse et la diversité de l'ancienne fête de la mi-carême.

Carmen D'Entremont Université Sainte-Anne, Pointe-de-l'Église

Belmont, Nicole et Élisabeth Lemirre (dir.). Sous la cendre. Figures de Cendrillon. Anthologie établie et postfacée par Nicole Belmont et Élisabeth LemirRe. Paris, Librairie José Corti, « Collection Merveilleux » 34, 2007, 423 p. ISBN 978-2-7143-0957-0.

«Cendrillon est sans doute le conte le plus connu, le plus répandu, le plus aimé. Mais les récits de Charles Perrault et des frères Grimm, parce qu'ils ont été écrits, imprimés et diffusés largement, ont fini par constituer un écran qui soustrait à nos regards les centaines, peut-être les milliers d'autres versions recueillies par les ethnologues et les folkloristes. Avec ce recueil, on aimerait faire connaitre les nombreuses figures de Cendrillon [...]» (p. [7]). Voilà comment Nicole Belmont formule le dessein de cet ouvrage : donner à lire des figures de l'orpheline brimée par sa marâtre, telles que les restituent les narrations de nombreuses cultures étalées sur tous les continents et dont la plus ancienne connue (p. 242-245) aurait été relevée en Chine au IX ${ }^{\mathrm{e}}$ siècle.

On sait que la réunion de versions d'un même conte n'a rien d'un simple collage ; c'est au contraire une entreprise longue qui implique d'abondantes lectures. Que la fin poursuivie soit une étude comparative - auquel cas l'exhaustivité est souhaitable - ou, comme ici, une anthologie - qui entend publier les diverses « figures » du type Cendrillon -, le recours au catalogue international des contes populaires, disponible dans sa troisième révision depuis 2004, facilite le repérage des récits qu'on a indexés depuis un siècle ; une « table alphabétique et typologique » réfère d'ailleurs à l'édition refondue de ce catalogue par Hans-Jörg Uther (The Types of International Folktales, based on the System of Antti Aarne and Stith Thompson, Helsinki, Academia Scientiarum Fennica, « FFC » 284, 285 et 286, 2004 [AтU]). 